\title{
SIMULAÇÃO DE UMA COLUNA DE DESTILAÇÃO REATIVA DE NAFTA PARA HIDROGENAÇÃO DO BENZENO
}

\author{
N. G. KHOURI ${ }^{1}$, D. SIDRÃO ${ }^{1}$, M. Z. FRANCATTO ${ }^{1}$ e V. O. CÁRDENAS CONCHA ${ }^{1}$ \\ ${ }^{1}$ Universidade Federal de São Paulo, Setor de Engenharia, Departamento de Ciências Exatas \\ e da Terra $-\mathrm{F}$ \\ E-mail para contato: nadia-2912@hotmail.com
}

\begin{abstract}
RESUMO - A gasolina, elemento indispensável para a sociedade moderna, possuí em sua composição compostos prejudiciais à saúde humana. Dentre estes, o benzeno é uma substância cancerígena formada nos processos de reforma catalítica da nafta, que promovem o aumento de octanagem da gasolina. A corrente de benzeno após este processo possui concentrações na faixa de 8 a 10\% (v/v); contudo, a Agência Nacional do Petróleo, Gás Natural e Biocombustíveis (ANP) regulamenta o máximo de 1\% (v/v). Uma opção muito vantajosa para retirar benzeno da corrente de nafta é realizar a sua hidrogenação pelo processo de destilação reativa, pois devido à integração energética, o calor gerado pela reação é aproveitado para melhorar a eficiência de destilação, o que reduz custos com energia e instalação. Portanto, foi realizado neste trabalho a simulação de uma coluna de destilação reativa de nafta para hidrogenação de benzeno utilizando o software Aspen Plus ${ }^{\circledR}$. Assim, utilizando o modelo termodinâmico de Peng-Robinson, obteve-se uma eficiência de hidrogenação do benzeno no leito catalítico de $99,22 \%$, que resultou na redução volumétrica da concentração de benzeno na nafta de $6,158 \%$ para $0,047 \%$, ou seja, valor abaixo do $1 \%$ (v/v) regulamentado pela ANP. Além disso, houve uma recuperação de 99,64\% de tolueno, sendo que sua hidrogenação ocorre de forma análoga ao benzeno, porém é uma reação não é desejada, pois o tolueno aumenta a octanagem do combustível e não tem concentração prevista por legislação.
\end{abstract}

\section{INTRODUÇÃO}

Nas últimas décadas, o desenvolvimento dos processos industriais não é focado apenas em melhorias e no aumento da eficiência produtiva, mas também se preocupa em gerar mais produtos utilizando menos recursos, aumentando a competitividade na indústria química e petroquímica. Entretanto, a preocupação no desenvolvimento de novos processos industriais vai além do aspecto econômico, pois o fator ambiental se destaca continuamente devido ao gradual aumento nas restrições ambientais e nos impactos causados por produtos químicos e petroquímicos na saúde e bem-estar humano. Neste contexto, a gasolina, produto da indústria petrolífera e difundido no cotidiano da sociedade moderna, é formada por uma mistura de hidrocarbonetos - na faixa de C6 a C10 - e aditivos, de forma que alguns destes compostos são prejudiciais à saúde humana. Assim, a composição da gasolina sofreu diversas restrições ao longo dos anos. Aditivos contendo chumbo foram banidos da gasolina na maioria dos países e o benzeno, produto com poder carcinogênico, tem sido gradativamente reduzido, restrito a um percentual máximo de $1 \%$ de volume na Europa a partir de 2000 


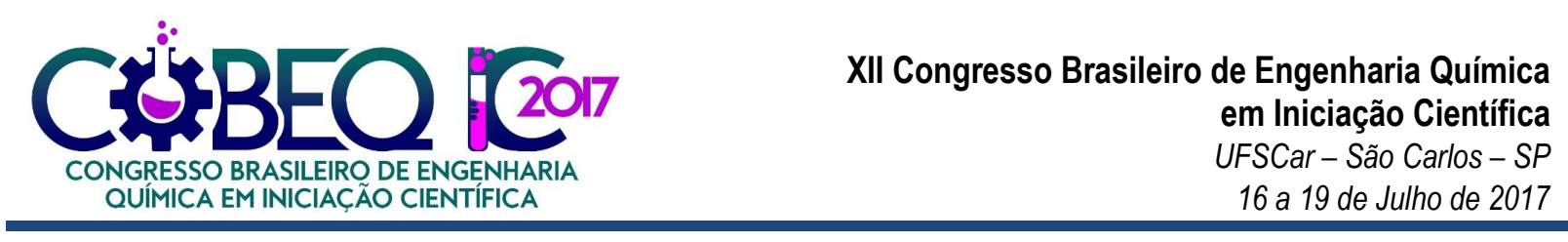

(ULLMANN'S, 2003). No Brasil, a Agência Nacional do Petróleo, Gás Natural e Biocombustíveis (ANP) define um percentual máximo de $1 \%(\mathrm{v} / \mathrm{v})$ de benzeno na gasolina (Agência Nacional do Petróleo, Gás Natural e Biocombustíveis, 2013).

A maioria do benzeno presente na gasolina é originado durante os processos de reforma catalítica da nafta, que altera parte dos componentes da mistura para outros com maior estabilidade e consequentemente, maior taxa de octanagem, sendo que muitos destes são compostos aromáticos (ALUKO, 2008). Desta forma, o processo de produção da gasolina visa gerar um combustível com alta octanagem (menor taxa de autoignição) e regulamentado pelos padrões ambientais estabelecidos. Assim, o foco deste trabalho foi a hidrogenação do benzeno em ciclohexano pelo processo de destilação reativa como possível processo para a diminuição da composição de benzeno da gasolina.

A destilação reativa é uma operação onde o processo de separação e reação química ocorre simultaneamente em um único equipamento. Este processo integrado surgiu como uma alternativa aos processos de destilação e reacionais que ocorrem separadamente em diferentes equipamentos. Na destilação reativa, uma coluna de destilação é incrementada com um leito catalítico reacional, tornando possível a integração das operações (SUNDMACHER; KIENLE, 2002). A Figura 1 esquematiza o fluxograma do processo tradicional de produção do acetato de metila e o mesmo processo realizando destilação reativa.

Figura 1: Fluxograma do processo de produção do acetato de metila por destilação reativa (a) e pelo processo tradicional (b).

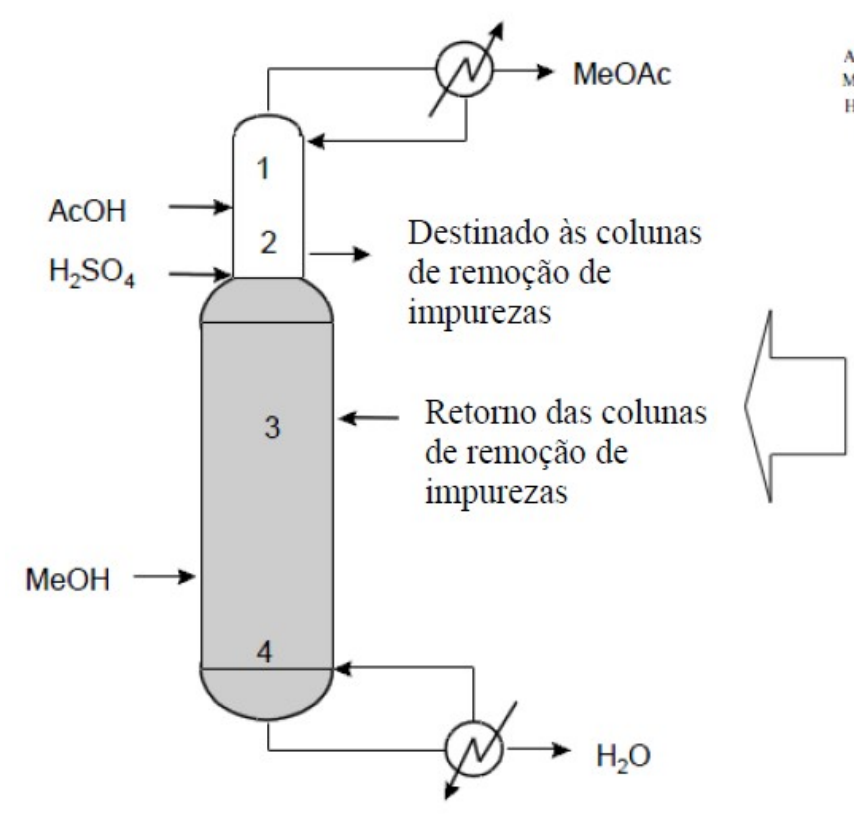

(a)

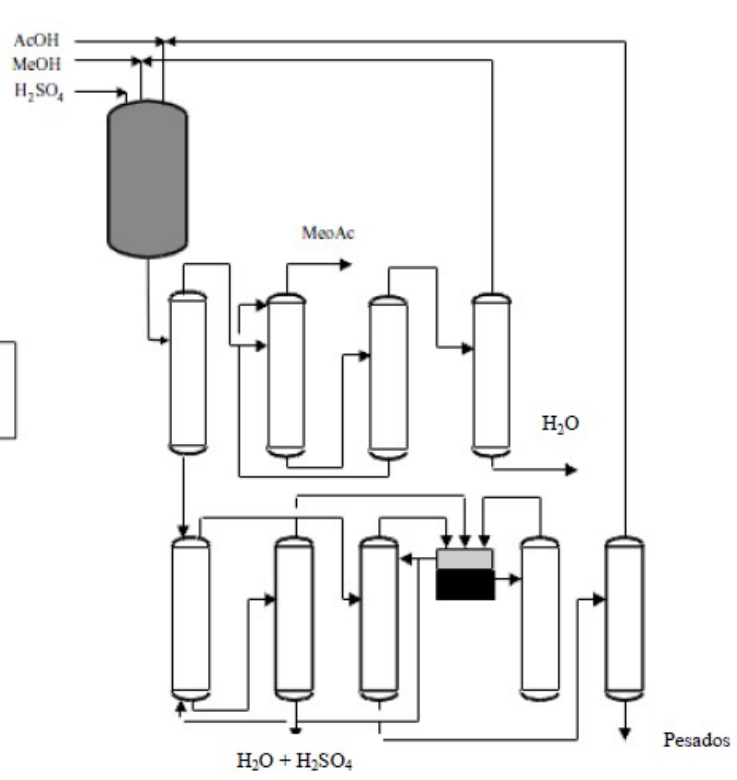

(b)

Fonte: MAHINDRAKAR; HAHN, 2008.

Desta forma, ao comparar a destilação reativa aos processos convencionais, destaca-se que ao combinar dois equipamentos em apenas um, há uma considerável redução nos custos para aquisição de bombas, instrumentações e tubulações. Além disso, quando a reação do 
processo é exotérmica, o calor produzido por essa pode ser utilizado no processo de destilação, diminuindo a quantidade de energia necessária no refervedor, e devido à rápida remoção dos produtos da zona reacional, a seletividade aos produtos pode aumentar e a probabilidade de ocorrerem reações consecutivas pode diminuir; e também se o processo de separação ocorrer antes da reação, o envenenamento do catalisador pode ser evitado, tornando o catalisador mais estável. (PODREBARAC; NG; REMPEL,1997).

Devido às interações entre reação e destilação em um mesmo equipamento, o comportamento operacional de tal processo pode se tornar bastante complexo e de difícil controle, exigindo a utilização de softwares de simulação como o Aspen Plus ${ }^{\circledR}$ para a realização do dimensionamento preliminar do equipamento. Desta forma, o objetivo do presente trabalho foi simular via software Aspen Plus ${ }^{\circledR}$ uma coluna de destilação reativa, para hidrogenação de benzeno proveniente de uma corrente de reforma catalítica da nafta para produção de gasolina. O benzeno deve ser reduzido a concentrações abaixo de $1 \%$ (v/v) para atender a regulamentação atual.

\section{MATERIAIS E MÉTODOS}

A destilação reativa é considerada uma operação complexa devido à presença simultânea dos equilíbrios químicos, de fase, líquido-vapor, líquido-líquido-vapor, além de considerar a atividade catalítica e cinética, transferência de massa nas interfaces gás-líquido e sólido-líquido, adsorção dos reagentes e dessorção dos produtos na superfície do catalisador. (KISS et al., 2006). Portanto, os cálculos manuais são inviáveis devido à alta complexidade da operação, tornando necessário a utilização de softwares de simulação para a predição do comportamento do processo. Neste contexto, este trabalho utilizou o software de simulação de processos Aspen Plus ${ }^{\circledR}$ (Aspentech) para simular uma coluna de destilação reativa para separação e hidrogenação de benzeno em uma corrente de nafta proveniente da reforma catalítica. Utilizando os modelos de colunas $R A D F R A C$ do Aspen Plus ${ }^{\circledR}$ inserirem-se dados de estequiometria e cinética das reações desejadas, além de definir em quais pratos será implementado o leito catalítico. A corrente definida para a alimentação da coluna de destilação reativa é constituída por nafta reformada com a composição mostrada na Tabela 1.

Tabela 1 - Composição da alimentação

\begin{tabular}{cc}
\hline Componentes & Fração molar \\
\hline n-Butano & 0,0126 \\
\hline n-Pentano & 0,0961 \\
\hline 2,3-Dimetilpentano & 0,0116 \\
\hline 3-Metilhexano & 0,0233 \\
\hline n-Hexano & 0,0350 \\
\hline Benzeno & 0,0826 \\
\hline 3-Metilhexano & 0,0233 \\
\hline 2,4-Dimetilpentano & 0,0234 \\
\hline n-Heptano & 0,0098 \\
\hline Tolueno & 0,2814 \\
\hline
\end{tabular}




\begin{tabular}{cc}
\hline m-Xileno & 0,2063 \\
\hline Cumeno & 0,1594 \\
\hline
\end{tabular}

Fonte: MAHINDRAKAR; HAHN, 2008.

O modelo termodinâmico selecionado para este estudo foi o Peng-Robinson (PR) (PENG; ROBINSON, 1976). Além disso, a simulação da coluna de destilação reativa requer a entrada de dados de cinética química para os compostos que sofrem hidrogenação, no caso o benzeno e o tolueno. Apesar da consideração de que o tolueno é rapidamente removido pelo fundo da coluna, sem que chegue à seção reativa, dados cinéticos para este foram considerados na simulação, assim foram considerados parâmetros com temperatura de referência em 373,15 K, mostrada na Tabela 2.

Tabela 2: Parâmetros para cinética de reação de benzeno e tolueno à 373,15 K.

\begin{tabular}{ccc}
\hline Parâmetro & Benzeno & Tolueno \\
\hline $\mathrm{k}\left(\mathrm{mol} \cdot \mathrm{m}^{6} /\left(\mathrm{s} . \mathrm{kg} \cdot \mathrm{mol}^{2}\right)\right)$ & $1,50 \mathrm{E}+12$ & $7,82 \mathrm{E}+11$ \\
\hline $\mathrm{Ea}(\mathrm{J} / \mathrm{mol})$ & 37700 & 38700 \\
\hline
\end{tabular}

Fonte: TOPPINEN et al.,1996.

Por outro lado, os parâmetros de operação iniciais da coluna de destilação reativa e as condições iniciais das correntes de entrada no processo foram baseados nos parâmetros definidos por MAHINDRAKAR e HAHN, 2014. A Tabela 3 apresenta os parâmetros de projeto adotados para a coluna de destilação e a Tabela 4 apresenta os parâmetros iniciais das correntes de entrada.

Tabela 3: Parâmetros de projeto da coluna de destilação.

\begin{tabular}{cc}
\hline Número de estágios & 70,0 \\
\hline Razão de Refluxo & 4,3 \\
\hline Pressão (kPa) & 792,4 \\
\hline Temperatura do condensador (K) & 389,2 \\
\hline Temperatura do reboiler (K) & 850,0 \\
\hline Diâmetro (cm) & 300,0
\end{tabular}

Fonte: adaptado de MAHINDRAKAR; HAHN, 2014.

Tabela 4: Parâmetros iniciais das correntes de entrada.

\begin{tabular}{ccc}
\hline & Hidrogênio & Nafta \\
\hline Temperatura (K) & 430,0 & 430,0 \\
\hline Pressão $(\mathrm{kPa})$ & 797,0 & 797,0 \\
\hline Vazão (mol/s) & 65,9 & 265,0 \\
\hline Estágio de entrada & 29 & 30 \\
\hline
\end{tabular}

Fonte: adaptado de MAHINDRAKAR; HAHN, 2014.

As correntes de hidrogênio e nafta entram na coluna nos estágios 29 e 30, respectivamente, para que a separação do tolueno ocorra antes da zona reacional e também previne que o benzeno desça para a corrente de fundo. Além disso, definiu-se um leito catalítico de níquel/alumina com 9 estágios de equilíbrio no topo da coluna, estágio 2 ao 11 , 
garantindo que a reação ocorra apenas após a separação das frações leves e pesadas da nafta na destilação. O recheio selecionado foi o Anel de Pall metálico de $25 \mathrm{~mm}$, fator de empacotamento de $157 \mathrm{~m}^{-1}$ e Altura Equivalente ao Prato Teórico (HETP) de 0,45m.

\section{RESULTADOS E DISCUSSÃO}

A Figura 2 apresenta o fluxograma do processo para uma coluna de destilação com recheio estruturado e leito catalítico no Aspen Plus ${ }^{\circledR}$

Figura 2: Fluxograma do processo em Aspen Plus ${ }^{\circledR}$

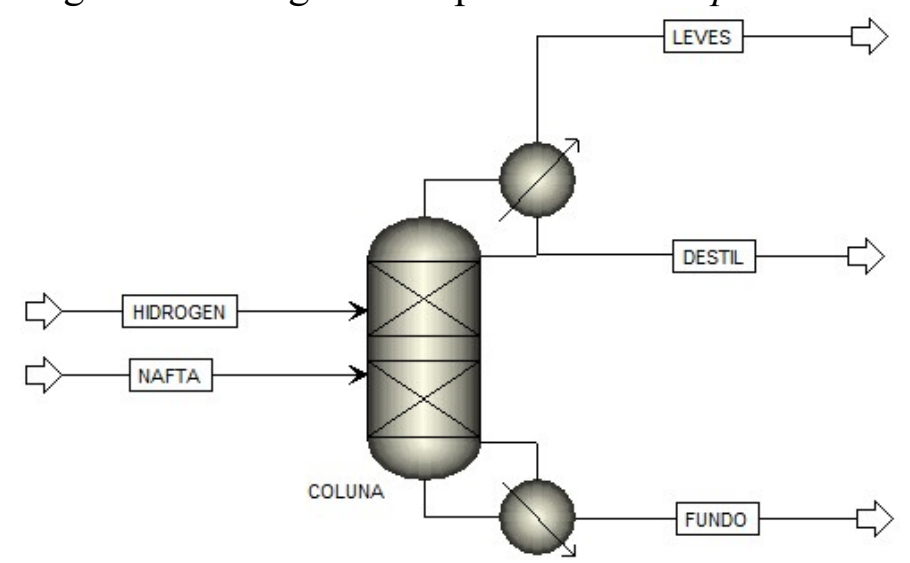

Fonte: fluxograma de processos Aspen Plus ${ }^{\circledR}$

A Tabela 5 apresenta os resultados da simulação inicial, com fração molar dos componentes em cada corrente e concentração volumétrica de benzeno na corrente de nafta e na somatória das três correntes de saída da coluna.

Tabela 5 - Resultados da simulação

\begin{tabular}{|c|c|c|c|c|c|c|}
\hline Corrente & Nafta & $\mathrm{H}_{2}$ & Destilado & Fundo & Leves & $\begin{array}{l}\text { Total } \\
\text { Saída }\end{array}$ \\
\hline Temperatura(K) & 430,0 & 430,0 & 389,2 & 496,3 & 389,2 & \\
\hline Pressão (kPa) & 797,0 & 797,0 & 792,4 & 792,4 & 792,4 & \\
\hline Vazão molar (mol/s) & 265,0 & 65,9 & 84,3 & 180,1 & 1,1 & \\
\hline Componente & \multicolumn{6}{|c|}{ Fração Molar } \\
\hline n-Butano & 0,013 & 0,000 & 0,039 & $1,59 \mathrm{E}-22$ & 0,085 & 0,013 \\
\hline n-Pentano & 0,096 & 0,000 & 0,298 & $1,81 \mathrm{E}-16$ & 0,313 & 0,096 \\
\hline 2,3-Dimetilpentano & 0,012 & 0,000 & 0,015 & 0,010 & $4,58 \mathrm{E}-03$ & 0,012 \\
\hline 3-Metilhexano & 0,059 & 0,000 & 0,183 & 6,31E-09 & 0,105 & 0,059 \\
\hline n-Hexano & 0,035 & 0,000 & 0,109 & $3,62 \mathrm{E}-08$ & 0,055 & 0,035 \\
\hline Benzeno & 0,082 & 0,000 & $6,65 \mathrm{E}-31$ & $9,44 \mathrm{E}-04$ & $2,69 \mathrm{E}-31$ & 0,001 \\
\hline 3-Metilhexano & 0,023 & 0,000 & 0,025 & 0,023 & $7,45 \mathrm{E}-03$ & 0,023 \\
\hline 2,4-Dimetilpentano & 0,023 & 0,000 & 0,073 & $4,83 \mathrm{E}-05$ & 0,029 & 0,023 \\
\hline n-Heptano & 0,010 & 0,000 & $5,98 \mathrm{E}-04$ & 0,014 & $1,55 \mathrm{E}-04$ & 0,010 \\
\hline Tolueno & 0,281 & 0,000 & $5,467 \mathrm{E}-24$ & 0,413 & $1,13 E-24$ & 0,280 \\
\hline
\end{tabular}




XII Congresso Brasileiro de Engenharia Química
em Iniciação Científica
UFSCar - São Carlos - SP
16 a 19 de Julho de 2017

Figura 2: Frações molares de benzeno e tolueno nos estágios da coluna

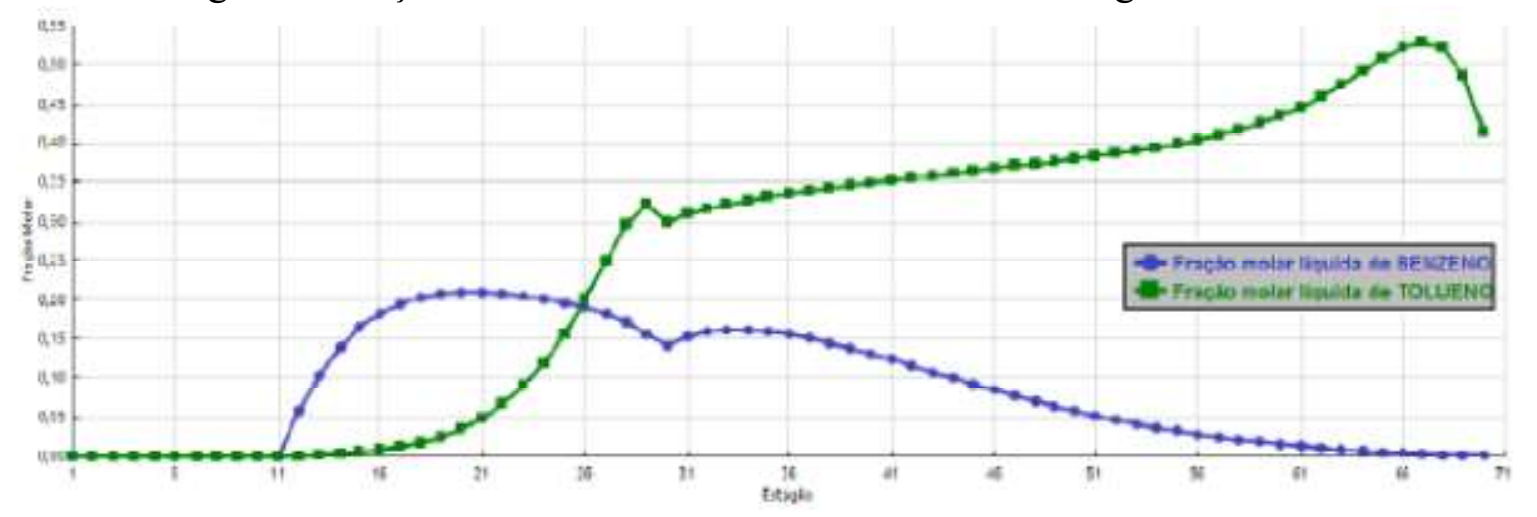

Fonte: Aspen

Analisando a Figura 2 nota-se que após a entrada do benzeno e tolueno no $30^{\circ}$ estágio da coluna, o primeiro tende a subir e entrar no leito catalítico, a partir do $11^{\circ}$ estágio, sendo hidrogenado em seguida. As frações molares de benzeno nos estágios mais baixos da coluna tendem a diminuir, atingindo 0,05 já no estágio 51 e se torna quase nula a partir do estágio 66 . Esta análise torna clara a eficácia do processo em não deixar que o benzeno saia pelo fundo da coluna, arrastando-o ao leito catalítico onde ocorre a sua hidrogenação à ciclohexano. Assim, a eficiência de hidrogenação do benzeno foi de $99,22 \%$ e a eficiência de recuperação de tolueno no processo foi de $99,64 \%$.

\section{CONCLUSÃO}

Com sua capacidade de integração reator-coluna de destilação, a destilação reativa mostrou-se promissora para a retirada de benzeno na produção de gasolina, visando atender às legislações vigentes, pois, reduz gastos em instalação e energia. Aplicando a destilação reativa ao processo, foi possível atingir $99,64 \%$ de recuperação de tolueno, demonstrando a eficiência da destilação proposta em separar os componentes desejados da nafta. Já a eficiência de hidrogenação do benzeno à ciclohexano no leito catalítico foi de $99,22 \%$, resultando em uma 
redução da concentração volumétrica de benzeno de $6,158 \%$, na entrada do processo, para $0,047 \%$ na somatória das vazões de saída, valor abaixo do $1 \%(\mathrm{v} / \mathrm{v})$ previsto pela legislação e objetivo deste estudo. Os resultados obtidos demonstram a eficácia do processo de destilação reativa, unindo duas operações complexas em apenas um equipamento capaz de realizar uma reação seletiva através da destilação de componentes do processo.

\section{REFERÊNCIAS}

ALUKO, O. Dynamic Modeling And Control Of Reactive Distillation For Hydrogenation Of Benzene. 2008. 66 p. Thesis (Master of Science). Texas A\&M University, College Station;

Agência Nacional do Petróleo, Gás Natural e Biocombustíveis. Resolução ANP No 40, de 25.10.2013. Acervo Digital de Legislação, Brasília,DF, 25 out. 2013. Disponível em: . Acesso em: 03 maio 2016, às 10:50;

CARLSON, E. C. Don't Gamble With Physical Properties For Simulations. [S.1.]: CHEMICAL ENGINEERING PROGRESS, 1996. 35-46 p.

KISS, A.; et al. The heterogeneous advantage: biodiesel by catalytic reactive distillation. [S.1.]: Topics in Catalysis 40, 2006. 141-150 p.

PENG, D. Y.; ROBINSON, B. A New Two-Constant Equation of State. [S.1.]: Industrial and Engineering Chemistry: Fundamentals, v. 15, 1976.

PODREBARAC, G. G.; NG, F. T. T.; REMPEL, G. More uses for catalytic distillation. [S.l.]: Chemtech, v. 27, 1997. 37 - 45 p;

SAKUTH, M.; PETERS, U. Process for cracking tertiary butyl alcohol in a reaction distillation column. [S.1.]: US Pat 5,849,971, 15 dez. 1998. 6 p.

SUNDMACHER, K.; A. KIENLE. Reactive Distillation: Status and Future Directions. Hoboken, New Jersey: Willey-VCH, 2002.

ULLMANN'S. Encyclopedia of Industrial Chemistry. 6a . ed. Hoboken, New Jersey: Willey-VCH, 2003. 